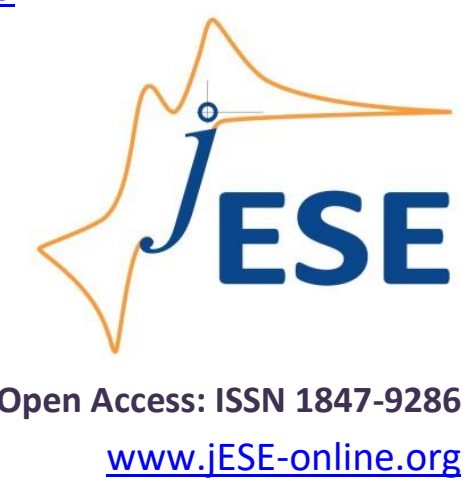

Review

\title{
Zdravko Stoynov - the scientist who created new scientific horizons
}

\author{
Daria Vladikova \\ Institute of Electrochemistry and Energy Systems, Bulgarian Academy of Sciences, \\ 10 Acad. G. Bonchev St., 1113 Sofia, Bulgaria \\ Corresponding author: ${ }^{\bowtie}$ d.vladikova@bas.bg \\ Received: January 7, 2020; Accepted: January 14, 2020
}

\begin{abstract}
This paper is in the memory of the big Bulgarian scientist Professor Zdravko Stoynov. An original and non-standard personality with the spirit of a gentleman, he turned all that he touched into a masterpiece. His innovative thinking which made him one of the world's leaders in Electrochemical Impedance Spectroscopy, chiseled away at the scientific taboos and created new scientific horizons. Zdravko Stoynov left us an abundant heritage - his spirit, his interminable capacity to wonder, his developments and inventions - all that he has taught us and brought up with. It has no dimensions but rather carries a unique value.
\end{abstract}

\section{Keywords}

Electrochemical impedance spectroscopy; 4-D analysis; rotating Fourier transforms; differential impedance analysis; differential resistance analysis.

\section{About Zdravko Stoynov}

Zdravko Stoynov left our world abruptly - engulfed in the ebullience of his latest series of advanced inventions. However, he left us an abundant heritage - his spirit, his interminable wonder and scientific curiosity which gave birth to remarkable developments and inventions which we must preserve, cherish, and augment. An original and non-standard personality with the spirit of a gentleman, he turned all that he touched into a masterpiece. His innovative thinking often made him feel like a scientific loner. Some of his developments were highly evaluated only 15-20 years after their invention, while others are still waiting to be accepted and implemented.

At the age of 24, Zdravko Stoynov builds the first in Bulgaria analog computer to calculate differential equations to the $12^{\text {th }}$ order. For over half a century right until his passing, he continues to create and develop algorithms \& solutions, which he integrates into his nonstandard equipment, to unveil new key phenomena in electrochemical power sources - the primary zone of his professional interest. 
Zdravko Stoynov's scientific achievements are not only numerous and significant, but also cross between different disciplines to redefine problems outside normal boundaries and reach solutions based on a new understanding of complex processes - a novel approach in modern science which usually involves different teams of scientists from diverse backgrounds and fields. Zdravko Stoynov's research combined electrochemistry with engineering, mathematics, computer sciences... he suited the equipment he created to his experimental goals - from the development of unique hardware and software to original methods for data analysis. For deeper insight into the underpotential prenucleation of $\mathrm{Ag}$ on dislocation free surface of single crystal face which could be observed in potential range 2-6 $\mathrm{mV}$, he constructed an ultra-sensitive potentiostat with a voltage range of 10 $\mathrm{mV}$ and precise control, stability and sensitivity of the potential, thus ensuring amplitude of the AC signal of $0.05 \mathrm{mV}$. His precise equipment and methodology were able to register impedance of a single dislocation.

Zdravko Stoynov's extensive inter-disciplinary knowledge and skills are reflected in his academic degrees: Ph.D. in engineering (automation of the experiment) from the Bulgarian Academy of Sciences (BAS), Doctor of Technical Sciences (Technical Cybernetics) from Swiss Federal Institute of Technology Zurich, and Doctor of Chemical Sciences from BAS.

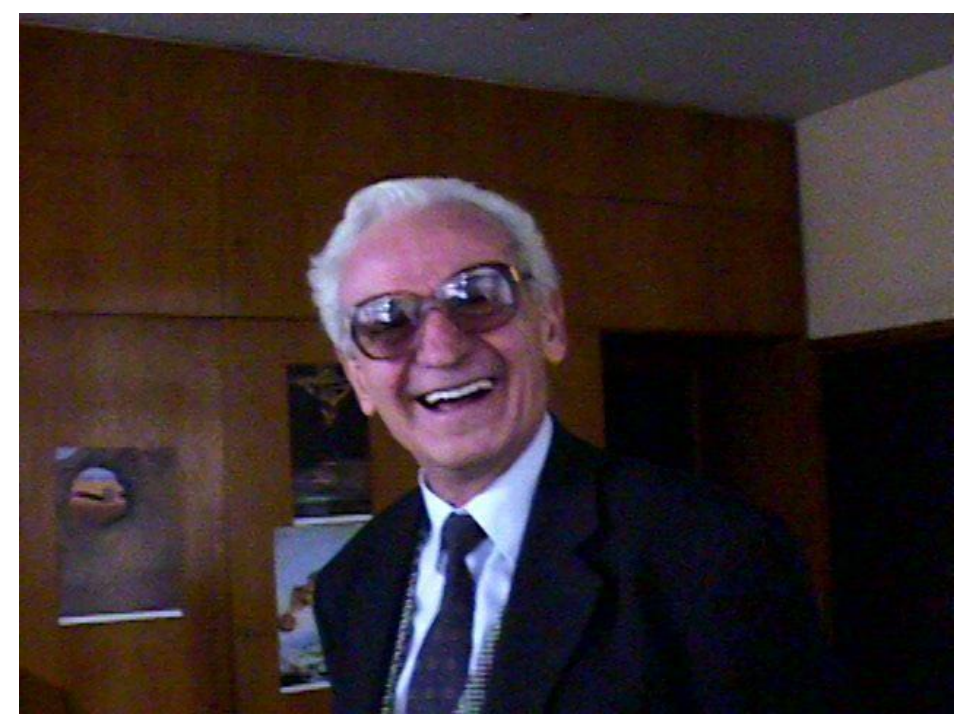

2010: Zdravko Stoynov in his cabinet as director of the Institute of Electrochemistry and Energy Systems, $B A S$, Sofia, Bulgaria

There is an unavoidable question put by many of Zdravko Stoynov's colleagues: what is the source of such limitless scientific curiosity and inexhaustible constructive energy to define new topics and undertake seemingly insoluble problems, transforming them into fertile and attractive research fields? The answer can be found in the words of the renowned physical chemist Ivan Stransky: " $A$ scientist must possess the capability to wonder. He has to see voids where others see nothing." These words are perfectly suitable for Zdravko Stoynov who managed to preserve and develop his childish curiosity and disregard for limits and taboos which, combined with exceptional intelligence and multidisciplinary knowledge accumulated during the years, made him an extraordinary scientist.

\section{The scientist}

Zdravko Stoynov graduated from the Technical University of Sofia in 1960 by constructing the first analog computer in Bulgaria as his master's thesis. In the next 2 years, he established the "Computing and Modeling Laboratory" at the Technical University and constructed a larger analog computer to calculate non-linear differential equations up to the $120^{\text {th }}$ order [1]. At the same time, 
he developed non-standard equipment for researchers at the BAS. As a result, in 1963 he was introduced to Evgeni Budevski, who in that time feverishly worked with his team on growing a dislocation-free single crystal, an extremely sensitive object. If they succeeded, the first "perfect crystal" in the world would be produced, experimentally confirming the Stransky-Kaischew theory of two-dimensional nucleation. Thus, Zdravko Stoynov became a part of a talented world-renowned research team on the verge of significant scientific discovery. In a matter of months, he considerably increased sensitivity, precision, and stability of the measuring equipment and although coming from a completely different scientific field, he started to participate actively in the scientific work. In a contribution about Academician Evgeni Budevski's life and scientific achievements [2], Zdravko Stoynov describes expressively the atmosphere, emotions, and dedication of the entire team during those exiting times. In 1965, thirty-three years after the publication of the Stransky-Kaischew theory, its experimental proof was finally obtained. First in the world, Budevski's team successfully grew the dislocation-free single crystal. This accomplishment has sparked extensive electrochemical studies in a new, experimentally unexplored system with completely different behaviour from systems with dislocations in the crystal lattice. Zdravko Stoynov is in the heart of this research, developing models for surface diffusion and monoatomic layer growth $[3,4]$.

With such a strong scientific start, what to do next?

The exceptional engineering and mathematical background give Zdravko Stoynov the unique independence to develop targeted task specific equipment. From then, he has the freedom to choose what scientific peak to overcome next, and he selected a difficult and little exploited, but yet exciting field, full of potential and enormous opportunities - Electrochemical Impedance Spectroscopy (EIS). In parallel, he continues to work in a pure engineering field - automation of the scientific experiment.

In 1967, the Central Laboratory of Electrochemical Power Sources (CLEPS) was established, with director Prof. Evgeni Budevski. The young experienced engineer Zdravko Stoynov, a head of the newly founded Department of Electrochemical Methods, builds the needed equipment. Thus, CLEPS laboratories started operating with automated powerful testing stations which could not be purchased on the market and were also implemented in the Bulgarian lead acid battery plants.

Currently the equipment of Department of Electrochemical Methods covers the range from 0.1 to $1000 \mathrm{~A}$.

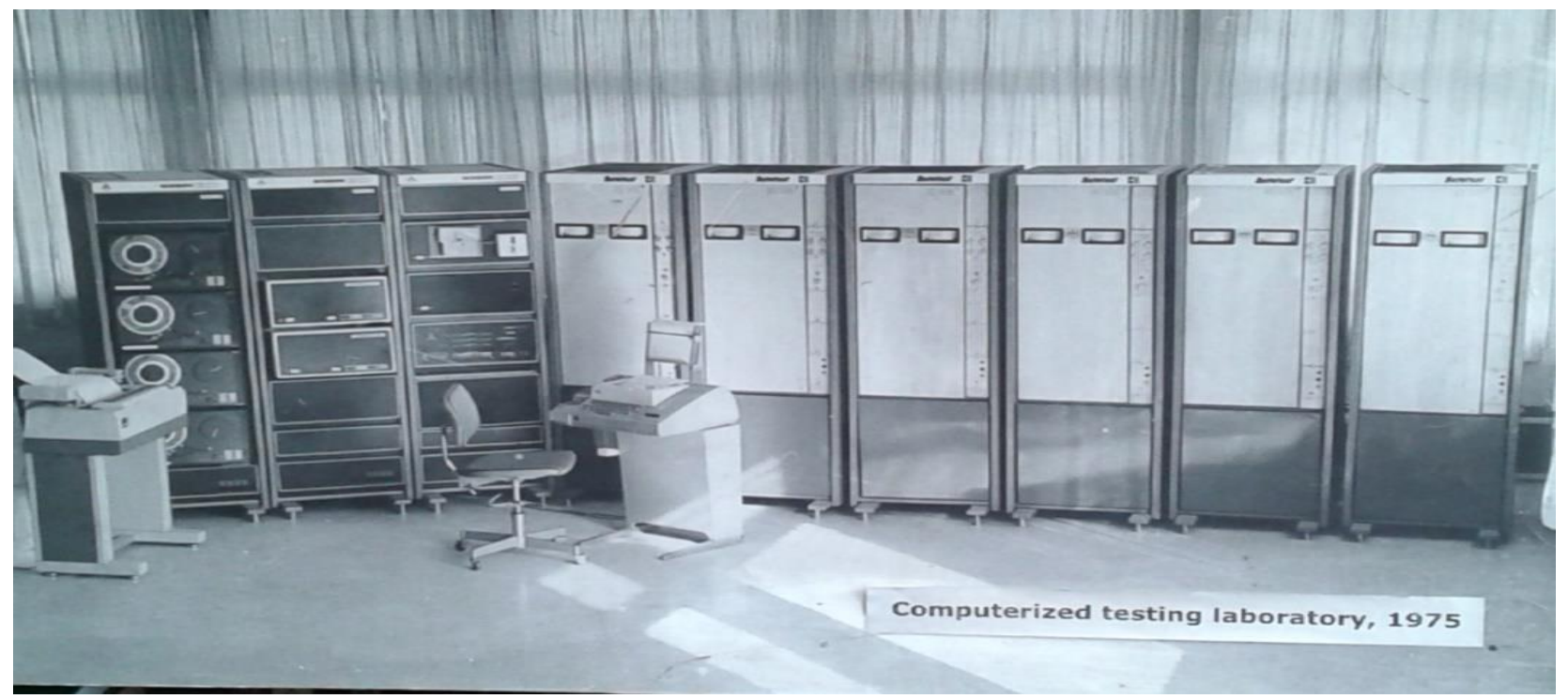

Zdravko Stoynov's computerized testing laboratory in CLEPS (1975) 


\section{Electrochemical Impedance Spectroscopy}

Gradually, the development of non-standard original equipment for specialized electrochemical studies turned from a target into a tool, while the objectives shifted towards the invention of sophisticated experimental methods. Zdravko Stoynov started to develop innovative approaches and techniques for electrochemical studies and characterization of different systems. Despite his interest and work in various scientific fields, his greatest and undying love remained to be electrochemical impedance. Very soon he becomes one of the world leaders in EIS which today is evaluated as a powerful method for thorough investigations of a wide scope of systems and processes.

What has attracted Zdravko Stoynov to EIS method? ... the unique information opportunities and numerous challenges that he tried to overcome during the course of over half a century - to his last breath.

Nowadays, measuring electrochemical impedance with frequency response analyzers is the mainstream method used in thousands of laboratories. However, only the few know that Zdravko Stoynov implemented this equipment into electrochemical measurements after a visit to the Solartron company in 1968. The same year, the first two frequency response analyzers were bought and introduced by Prof. Israel Epelboin in his laboratory in Paris (CNRS-UPMC, Université Pierre et Marie Curie) and Zdravko Stoynov in CLEPS (BAS).

The next challenge was "impedance of batteries" - an experiment which correlates with both the applied and research activities of CLEPS, and which was considered impossible at that time. However, Zdravko Stoynov starts to systematically chisel away at the scientific taboos.... till his last day.... with never ending enthusiasm and dedication. For a start, he introduces measurements out of equilibrium. Today this is customary, but 40 years ago it was unacceptable. He builds specialized equipment and with his colleagues at CNRS in Paris measure, for the first time in the world, impedance of batteries-galvanostatically and quasi-stationary [5]. The year is 1977. Today, 40 years later, every company for electrochemical equipment produces systems for impedance testing of batteries. Obviously, science does not allow "taboos" and despite big and powerful expert teams that work today, it also needs pioneers.

SHORT COMMUNICATION

\section{Impedance measurement on $\mathrm{Pb} / \mathrm{H}_{2} \mathrm{SO}_{4}$ batteries}

M. KEDDAM, Z. STOYNOV, ${ }^{*}$ H. TAKENOUTI

Groupe de Recherche no. 4 du C.N.R.S. 'Physique des Liquides et Electrochimie', associé à l'Université P. et M. Curie, 4 place Jussieu, 75230 Paris Cedex 05, France

Received 4 March 1977

1. Introduction

Relatively few works have been carried out on $\mathrm{Pb} / \mathrm{H}_{2} \mathrm{SO}_{4}$ batteries from an electrochemical kinetics point of view. This is partly due to the
The purpose of this note is to demonstrate that it is technically possible to measure the impedances of electrochemical generators by means of a transfer function analyser over a very wide frequency range. The impedance measurements are

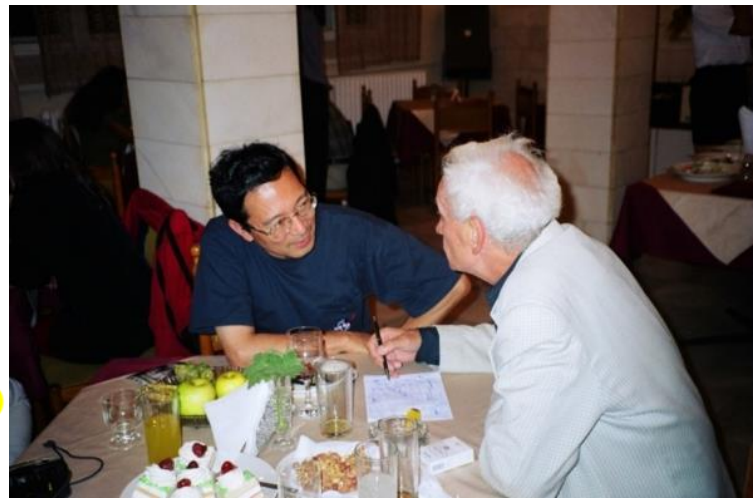

First publication on impedance of batteries, ref. [5] in 1977; 27 years later at the POEMES Workshop in Bulgaria, the co-authors Zdravko Stoynov and Hissasi Takenouti continue to enthusiastically discuss impedance (2004).

The next challenge comes from the non-steady state of batteries during impedance measurements. The solution is the development of the non-stationary (4-D) impedance analysis [6-13] which is quickly evaluated and adopted for testing of lithium-ion batteries by Mitsubishi [14,15], and later for studies of other time evolving processes [16,17]. Recently, 4-D impedance analysis was included in the software portfolio of Bio-Logic [18]. 


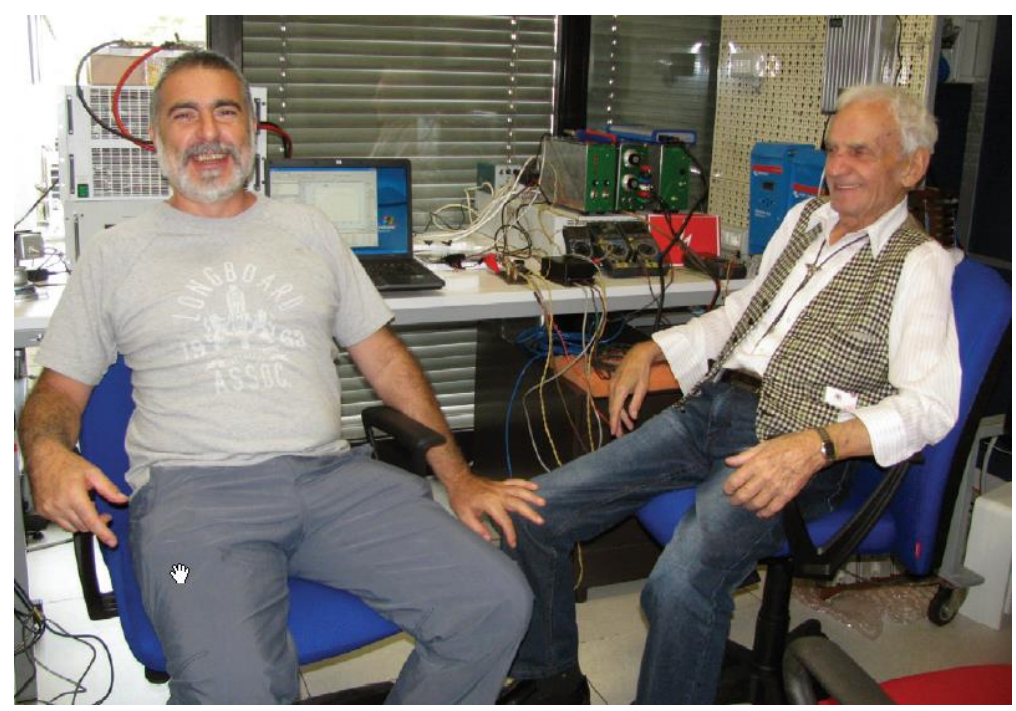

Zdravko Stoynov and Massimo Schiavetti in front of Stoynov's prototype equipment for "in operando" impedance testing of large batteries for accumulation of energy from solar cells (ENEL-Pisa, 2014).

\section{Other innovative approaches}

The list of Zdravko Stoynov's innovative approaches for electrochemical data analysis with enhanced information capabilities is long. Differential Coulometry Spectroscopy (DCS) [19] is introduced in the analytical package of the software version V11.01 of Bio-Logic Science Instruments [20]. Differential Impedance Analysis (DIA) in which structural identification which does not require preliminary hypothesis, is applied for the first time in impedance data analysis [21-27]. Rotating Fourier Transforms (RFT) is initially developed during his doctorship in Zurich $[28,29]$ - he concentrates on it again in his last and very creative year introducing new opportunities for impedance analysis at low and ultra-low frequencies where "many important and still hidden interesting phenomena can be measured precisely "[30]. His goal is the development of a new, " 4 th Generation" marketable impedance analyser, applying RFT and MRFT (Multiple RFT). He was expecting this to happen in the near future and was working hard to accelerate its coming. Zdravko Stoynov's latest invention is Differential Resistance Analysis based on original data processing from current-voltage curves. This method surprises and fascinates with simplicity and originality that provide over 10 times higher sensitivity when assessing degradation rate. This approach could eliminate some difficult and risky accelerated stress tests on batteries and fuel cells [31-33].

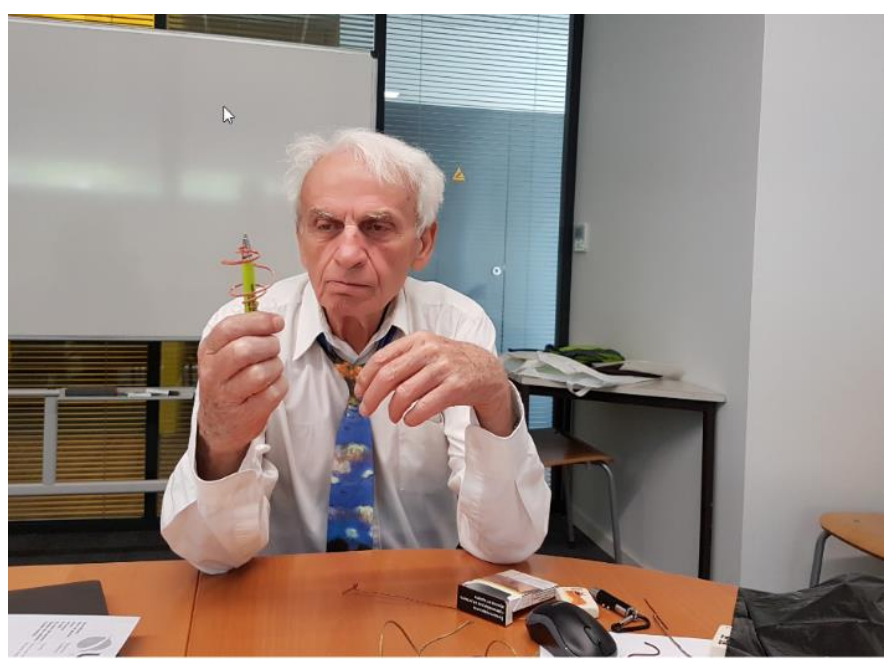

Bio-logic Science Instruments (Grenoble 2017): Zdravko Stoynov explaining visually his Rotating Fourier Transforms 


\section{International activities}

Although engulfed in science, Zdravko Stoynov is no less valued as a "social scientist" with an acute sense of establishment, with excellent teaching skills, and with a never- ending enthusiasm to educate and pass on his knowledge and know-how. He is one of the international impedance society founders - a similarly minded enthusiastic group of colleagues fascinated by the potential of electrochemical impedance. For over 30 years, the society has been gathering within the framework of two international conference chains:

- The International Electrochemical Impedance Spectroscopy Symposia (EIS), dating from 1989,

- The International Electrochemical Impedance Analysis Symposia (EIA), dating from 1988.

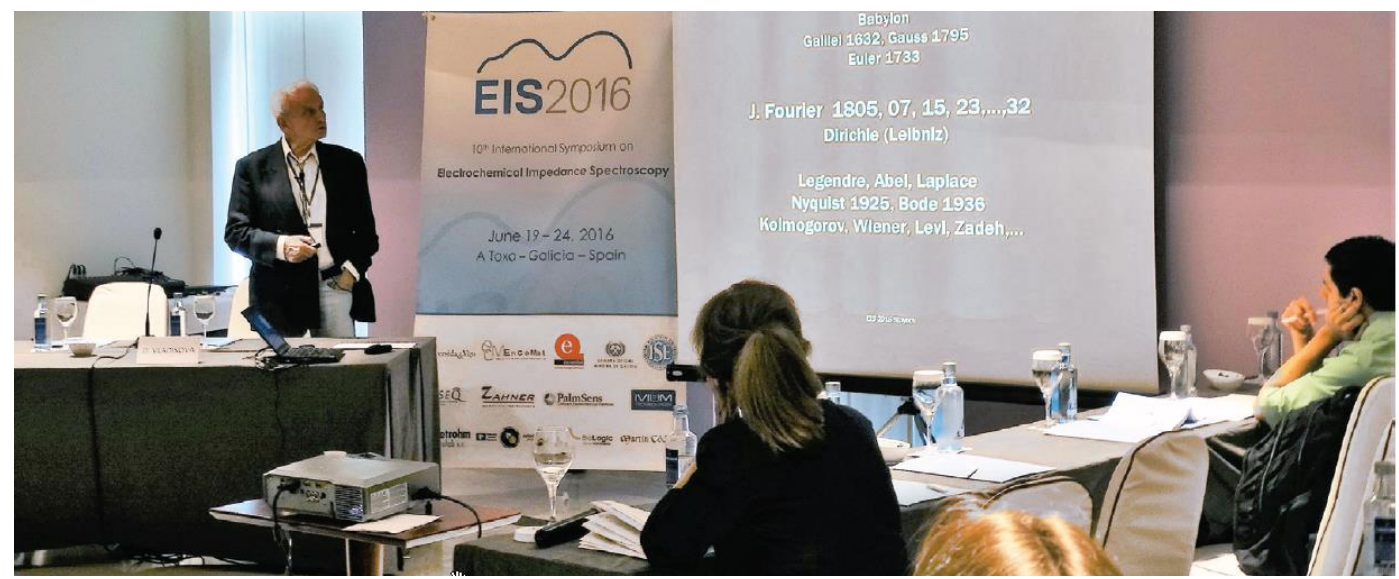

$10^{\text {th }}$ International Symposium on Electrochemical Impedance Spectroscopy (EIS), A Toxa, Galicia, Spain (2016). Lecture on Rotating Fourier Transforms (Zdravko Stoynov's last participation in EIS)

On a regional level, Zdravko Stoynov was one of the driving forces behind the establishment of the Regional Symposium of Electrochemistry - South-East Europe (RSE-SEE) in 2007, and acted as its co-organizer in Bulgaria, 2015. The $7^{\text {th }}$ Symposium held in May 2019 in Croatia was dedicated to his memory. Starting in 1996, Zdravko Stoynov also establishes the National electrochemical event with international participation "Sofia Electrochemical Days". Till his last day, Zdravko Stoynov continued to invigorate these scientific forums with his innovativeand avantgarde ideas.

\section{Recognition}

It is a quite rewarding experience to be able to reap what you have sown. Zdravko Stoynov could reap the respect and appreciation of his friends and colleagues from IEES, BAS, and all over the world, who joined together physically and virtually to celebrate his $80^{\text {th }}$ birthday, turning it into a joyous and heartwarming event. The Bulgarian Academy of Sciences honored his exceptional service with the special medal of the President of BAS, crowning and completing his BAS honors collection.

The international electrochemical community and the Bulgarian colleagues expressed their respect and gratitude to Zdravko Stoynov, who was named by his associate Digby McDonald from Berkeley-California as "a giant in the electrochemical impedance spectroscopy". The special issue of Bulgarian Chemical Communications has been dedicated to his $80^{\text {th }}$ anniversary and includes 30 publications by scientists from 13 countries.

Philosophers say that a man dies only when the memory of him is gone. The memory of Zdravko Stoynov will not fade. It will not be gone. It remains strong within the large international family of his students, colleagues, and friends from all over the world who honor, respect, and appreciate him. They named the Electrochemical Impedance Analysis Symposium and the Internet Center for 
Impedance Spectroscopy after him. The "Zdravko Stoynov" Prize in his honor will be awarded at each Meeting of the EIA to foster and promote creative out-of-the-box thinking in young researchers. The memory of Zdravko Stoynov is persistent, as are his deeds. All that he has sown and nurtured will continue to bear fruit into the future.

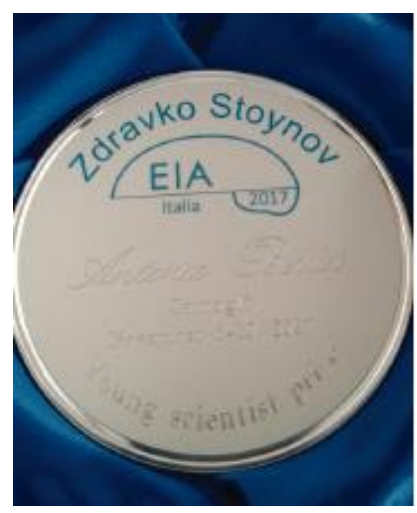

"Zdravko Stoynov" Young Scientist Prize

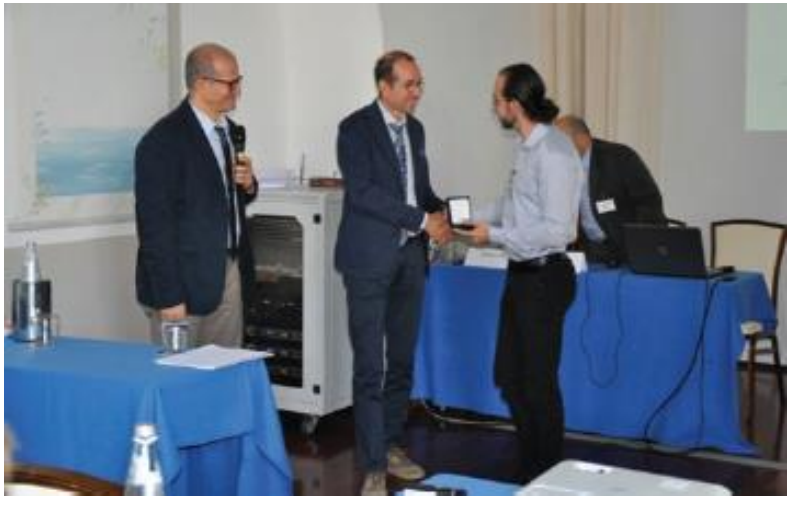

Awarding of "Zdravko Stoynov" Prize to its first recipient at the $11^{\text {th }}$ International Symposium of Electrochemial Impedance Anlysis (Camogli, Italy, Nov. 2017)

\section{Zdravko Stoynov's methods}

\section{Non-stationary (4-D) impedance analysis}

Based on the classical method of the transfer function, Electrochemical Impedance Spectroscopy gives a local, linearized and full (in a frequency aspect) description of the investigated electrochemical system, which is assumed to be in steady-state. However, batteries behave as big statistical systems with distributed parameters on a macro and micro scale. During cycling, processes of mass and energy transfer take place. They change the object's structure and parameters. Thus, batteries show nonsteady state behavior, which is the basic restriction for correct impedance studies.

For further development of batteries, a liberation from the restriction of steady-state condition is generally needed. This motivated Zdravko Stoynov to develop the non-stationary (4-D) impedance analysis - an approach that eliminates the delay errors during frequency sweep by introducing the time for each measurement as the fourth parameter in the experimental data set [6-9] (Figure 1).

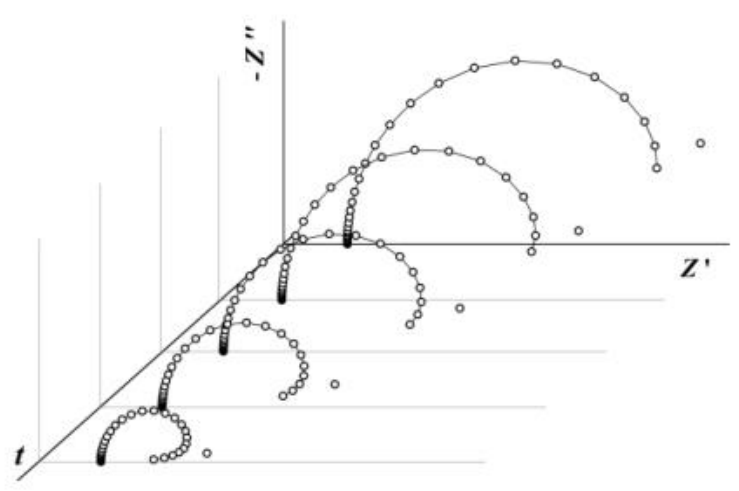

a)

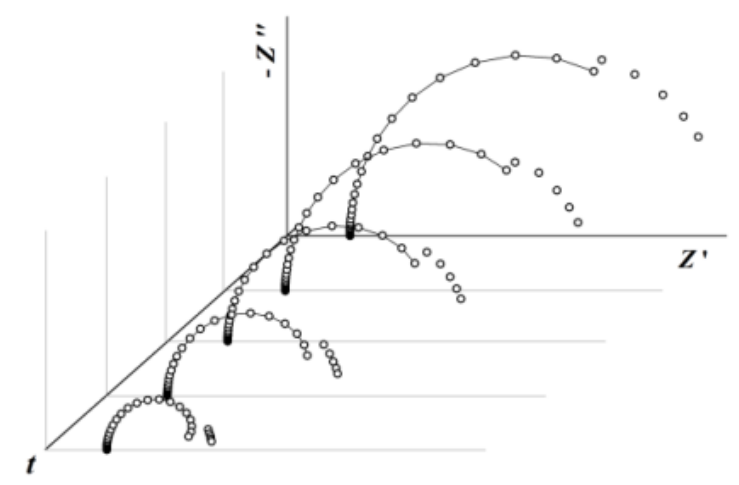

b)

Figure 1. Simulated complex-plane impedance diagrams of time evolving simple Faradaic reaction deformed by measurement delay errors: a) iso-frequency dependence for the lowest frequency; b) fifth iso-frequency dependence (starting from the lowest frequency). Reproduced from ref. [13] with permission from D. Vladikova

This approach improved significantly the impedance studies of batteries and other non-steady state systems [10-13]. Zdravko Stoynov approximates every iso-frequency dependence with a formal model and applies two orthogonal iso-frequency cubic splines for the real and the imaginary 
components, respectively. The interpolation (or extrapolation) for a given time, $t_{\mathrm{j}}$, and a set of frequencies $\omega_{\mathrm{i}}$, gives the corresponding estimates of the real and imaginary parts. Thus, the data of each time evolving diagram are reconstructed, and the corresponding impedance diagrams already represent the impedances measured virtually at the same time for all frequencies.

4-D impedance analysis was introduced in the battery testing software and successfully applied in Li-ion battery research $[14,15,18]$, and also for studies of some other time-evolving systems $[16,17]$.

\section{Rotating fourier transform (RFT)}

Non-steady state condition of electrochemical systems during impedance measurements penetrates deeper, affecting the Fourier Transform (FT), which is the mathematical kernel of every impedance analyzer of our days. The FT is the best estimator of sinusoidal signals in steady-state conditions. However, out of those conditions, the FT produces specific errors dependent on the frequency.

After an in-depth analysis of those errors, Zdravko Stoynov succeeds to develop theoretically an advanced generalized form of this transform - the Rotating Fourier Transform (RFT). This is the topic of his doctoral dissertation in the Federal Institute of Technology-Zurich [28,29]. The implementation of the RFT in impedance spectroscopy provides for precise measurements of time-evolving systems out of steady state conditions. It opens a new horizon for studies of batteries and fuel cells, corrosion and numerous other systems, far beyond the usually applied frequency range where "4-D impedance method seems to be the only method to easily remove the effect of time-variance" [18].

During the last year of his life, Zdravko Stoynov refocuses on further theoretical and experimental development of his advanced mathematical RFT tool, introduced 30 years ago. He describes it as a "powerful engine for non-stationary impedance spectroscopy which opens up the exploration of the low and infra-low frequencies where many important and interesting phenomena, still hidden, can

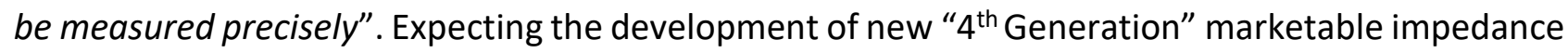
analysers through the application RFT and MRFT (Multiple RFT) in the near future, he labours over both the mathematical tool and his experimental verification (Figure 2) in order to accelerate the coming of this "near future" and to be able to see it. An unedited version of his last unpublished work on this topic, written months before his passing, is presented in the Proceedings of the $10^{\text {th }}$ International Symposium of Electrochemical Impedance Analysis (Section "Letters to the Editor") [30]. His colleagues from IEES are very much hopeful and will support the continuation of his efforts and the realization of his idea.
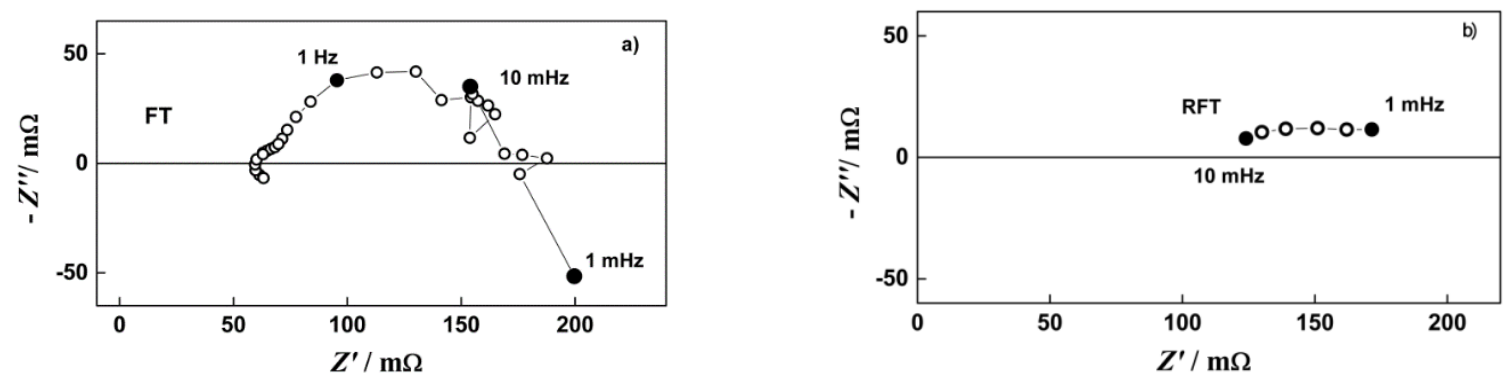

Figure 2. Complex-plane impedance diagrams of Li-ion battery $2000 \mathrm{mAh}$ during charge with $100 \mathrm{~mA}$ : (a) produced by conventional Impedance analyser (Solartron 1260) using Fourier Transform. Frequency range $1 \mathrm{kHz}-1 \mathrm{mHz}, 5$ points/decade, AC signal $11 \mathrm{~mA}$; (b) produced by Rotating Fourier Transform of the data from Fig. 2a. Frequency range $10 \mathrm{mHz}$ to $1 \mathrm{mHz}, 5$ points/decade [30].

\section{Differential coulometry spectroscopy (DCS)}

Battery testing is an important application-oriented tool for evaluation of their operational capability and performance as sources of energy and power. The typical testing results give general 
information that represents the overall behaviour and thus does not support the analytical understanding of the processes taking place. To fill this gap, Zdravko Stoynov develops Differential Coulometry Spectroscopy (DCS) [19], which extracts valuable information about the batteries internal kinetics, electrochemical design, and life degradation.

The DCS technique requires measurements of the voltage changes with time followed by precise analysis with the technique of Spectral Transform (ST) of aperiodic functions [24,26]. In order to separate the thermodynamic kinetics from the masking dynamic effect of the intrinsically connected transport limitations, very slow-rate galvanostatic testing (charge/discharge) is required. In principle, the galvanostatic mode of testing is a sweep coulometry and provides for the evaluation of the quantity of electricity necessary for the propagation of the investigated process or its steps. The voltage-time $(U / t)$ dependence (Figure $3 a$ ) of an electrochemical cell measured during charge (or discharge) can be easily converted into a voltage - quantity of electricity dependence. The final relation can be presented as capacity/voltage $(C / U)$ applying the ST tool (Figure $3 b$ ).

The coulometric peak analysis provides for capacity evaluation of the different charge or discharge steps. The mapping of the peaks position and coulometric capacity and the analysis of their time dependence can be used for evaluation of battery state of health (SoH). The DCS can also provide valuable information about the degradation processes. It is useful tool for electrochemical studies of rechargeable batteries based on intercalation materials. Recently, DCS was included in the analysis package of BioLogic Science Instruments' EC-Lab software version V11.01 [20].

a

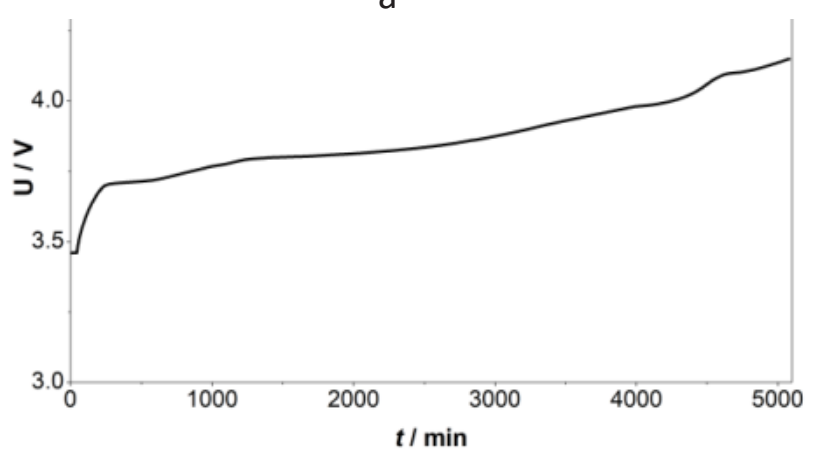

b

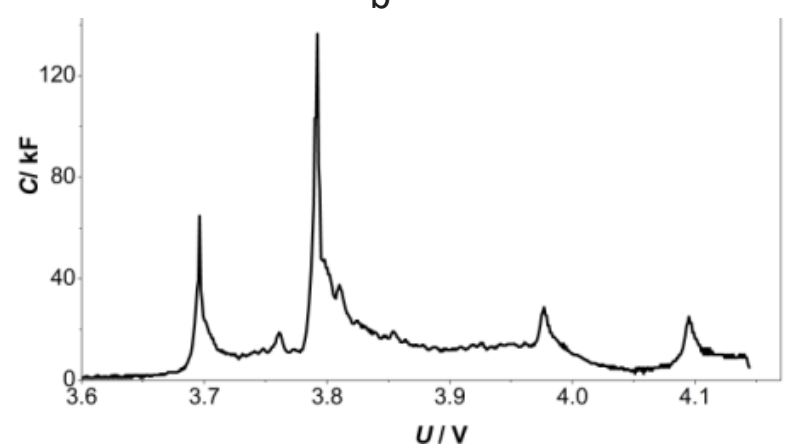

Figure 3. Four volts Li-ion sample with nominal capacity of $2200 \mathrm{mAh}$ : a) slow sweep voltage-time charge curve ( $\mathrm{h}=100$ hours); $b$ ) capacity spectrum of the slow sweep voltage-time charge and discharge curves ( $\mathrm{h}=100$ hours). Reproduced from ref. [19] with permission from D. Vladikova

\section{Differential impedance analysis (DIA)}

The introduction of Differential Impedance Analysis (DIA) method for electrochemical systems is one of the most advanced inventions of Zdravko Stoynov, in which for the first time the structural identification approach is applied in EIS.

As a transfer function, electrochemical impedance provides a local, linear, and complete description of the system under investigation. However, this information has to be extracted from the experimental data, since impedance does not directly measure the processes under study, i.e. the physical reality, but gives information about the response of the system on an external perturbation. The most commonly used approach for analysis of experimental data is the development of one or several working models followed by their validation. The model structure is chosen a priori, and thus the identification procedure is only parametric. The main efforts towards the improvement of the impedance data analysis are focused on the advancement of the identification procedure [33]. 
In technical cybernetics, the structural identification approach is applied for data analysis. It does not require an initial working hypothesis and provides both structural and parametric identification. Zdravko Stoynov develops the technique of Differential Impedance Analysis (DIA), introducing the structural identification approach in the frequency domain [21-27]. This is one of his biggest breakthroughs and example of his out-of-the-box thinking.

DIA procedure starts with the initial set of experimental data (angular frequency, real and imaginary components of the impedance), and thus can be applied to previously measured data. The kernel is the local scanning analysis, performed with the so-called local operating model (LOM) with a simple structure consisting of a resistance $R_{1}$ in series with a parallel connection of capacitance $C$ and a second resistance $R_{2}$. The effective time-constant $T=R C$ is also introduced as a LOM parameter.

In contrast to the classical parametric identification performed over the entire frequency range which estimates the parameters' vector as a preliminary chosen model structure, the identification of the LOM parameters' vector by local analysis is carried out within a narrow frequency range, regarded as an operating window. When the window width is a single frequency point, the solution is purely deterministic. The following steps describe the procedure of the structural and parametric identification:

- Scanning with the LOM throughout the whole frequency range with a scanning window of a single frequency point;

- Parametric identification of the LOM at every working frequency. Since the number of the independent data available inside the observation window is smaller than the number of unknown parameters, the initial set of impedance data is extended with two additional terms - the derivatives of the real and imaginary components of the impedance with respect to the frequency. Thus, the set of equations determining the LOM parameters estimation becomes solvable;

- Frequency analysis of the LOM parameters' estimates (Figure 4).
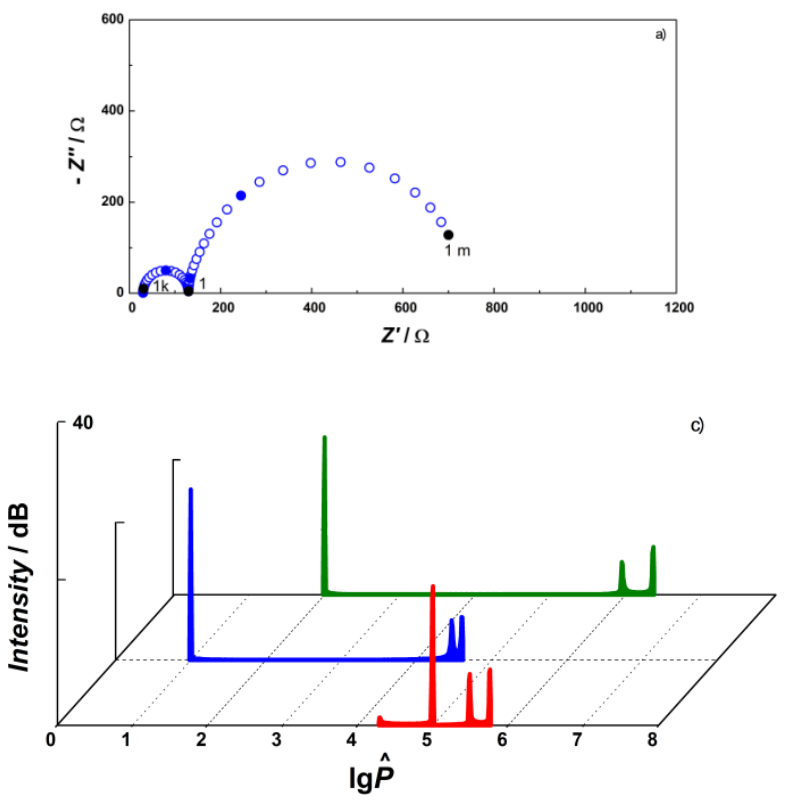
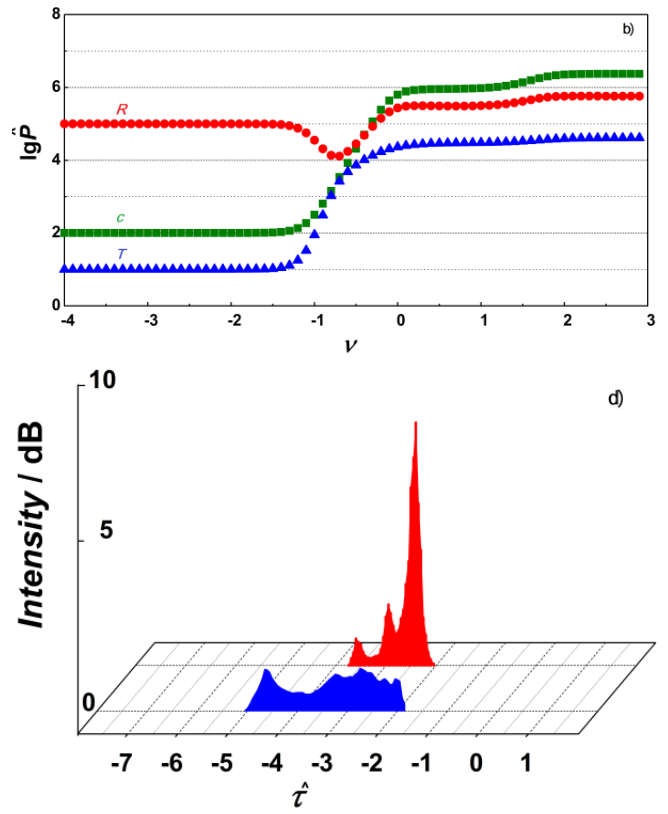

Figure 4. DIA of a three-step reaction: (a) complex-plane impedance diagram; (b) temporal plots (c) spectral plots; d) time-constant spectra of motor oil Mobil Delvac MX 15W40: new ( after $10000 \mathrm{~km}$. (Ш). Reproduced from ref. [26] with permission from D. Vladikova

The results are presented in so called temporal plots, which give the frequency dependence of the LOM parameters estimates (Figure 4b). If the LOM parameters' estimates are frequency independent in a given frequency region, the sub-model corresponding to this frequency segment 
follows the LOM structure, i.e. it is described with a parallel combination of capacitance and resistance, which determine a time-constant. Thus, the number of the plateaus gives the number of the time-constants in the model (Figure $4 b$ ).

The results may be presented in the more illustrative spectral form by the Spectral Transform procedure which converts the plateaus into spectral peaks by accumulating similar values of the respective parameters (Figure $4 c$ ) $[24,26,27]$. In principle the spectral transform is not simply a presentation of the same data in different coordinates. By its nature it is a type of regression analysis, filtering the statistical noises coming from the object itself and from the performed measurements, as well as the non-statistical noises. Its high power of filtration is eliminating the possible wild points and the resulting "black" noise, since the presence of an outlier introduces a fuzzy low intensity line, located away from the spectral kernel of the assembly, representing the investigated phenomenon. The amplitude of the spectral line is proportional to the frequency range with similar values of the corresponding parameters estimates.

The presence of frequency dependence in the temporal plots marks either the regions of mixing between two phenomena, or frequency-dependent behaviour. Instead of spectral peaks, the spectra form fuzzy spectral "tails". Those segments are additionally examined by Secondary DIA [25-27]. The procedure, known as Differential Temporal Analysis, includes the differentiation of the LOM parameters' estimates with respect to the log frequency. It recognizes frequency-dependent elements (CPE, Warburg, Bounded Warburg etc.), as well as their presence in more complicated models.

With DIA, Zdravko Stoynov opened new horizons for the impedance spectroscopy, increasing its objectivity, reliability and information capabilities (Figure 4d). The method is highly appreciated by the experts in the field of impedance spectroscopy and presented in recent monographs and surveys [35-38]. As an advanced development, DIA gradually enters in the impedance analysis and is already successfully applied for studies of electrochemical energy sources and other systems [39-48].

\section{Differential resistance analysis}

Zdravko Stoynov's final invention, developed in the last months of his life, is related to the most severe hurdles facing the deployment of batteries and fuel cells - lifetime and durability, and more precisely - their reliable evaluation."

The State-of-the-Art degradation already requires long-term testing, which can take several years - a huge restriction to market deployment. For the moment, the problem-solving approach consists in the development of accelerated stress test (AST) procedures and protocols, which should shorten the testing time in conditions activating the same aging mechanisms as in non-accelerated testing. This is a critical moment, since the measured degradation should be transferred to the real-life behaviour of the tested system. Thus, the selection of the acceleration parameters and the level of acceleration are of critical importance and may differ significantly between systems and applications.

Zdravko Stoynov offers a new and original approach that decreases the testing time by increasing the sensitivity and accuracy of the standard monitoring and diagnostic tools, providing reliable quantitative information. For this purpose, he introduces new performance indicator with increased sensitivity in respect to degradation evaluation. It is based on analysis of the standard currentvoltage characteristics, which describe the interrelation between the power components - voltage and current. One effective direction which Zdravko Stoynov develops is the analysis of the differential resistance - an approach which is not still effectively exploited.

The form of the volt-ampere characteristics depends on the operating parameters and the degradation processes. Under constant operating conditions, its changes are due to degradation. The next step is the introduction of an algorithm for their characteristic description. For this 
purpose, Zdravko Stoynov developed differential analysis of current-voltage curves (DiVA). The method operates with the differential resistance $R_{\mathrm{d}}=\mathrm{d} U / \mathrm{d} l$, i.e. with the derivative of the potential $U$ with respect to the current $I$, which changes its value according to the working point, following the shape of the volt-ampere curve [31-33].

The analysis of the Differential Resistance (DRA) as a function of the applied current $R_{\mathrm{d}}=f(I)$ (Figure 5a) works with derivatives, which increases the sensitivity in respect to the small deviations which should be recorded. The new functional dependence defines a new characteristic point for the cell performance - the minimum of the differential resistance $R_{\mathrm{d} \text {,min. }}$ In general, it reflects the state of health $(\mathrm{SoH})$ at constant operating conditions, since it is determined by the intrinsic properties of the system and not by the external conditions (for instance current load). It is supposed that for deeper insight, impedance measurements should be performed also in a working point corresponding to $R_{d, m i n}$.
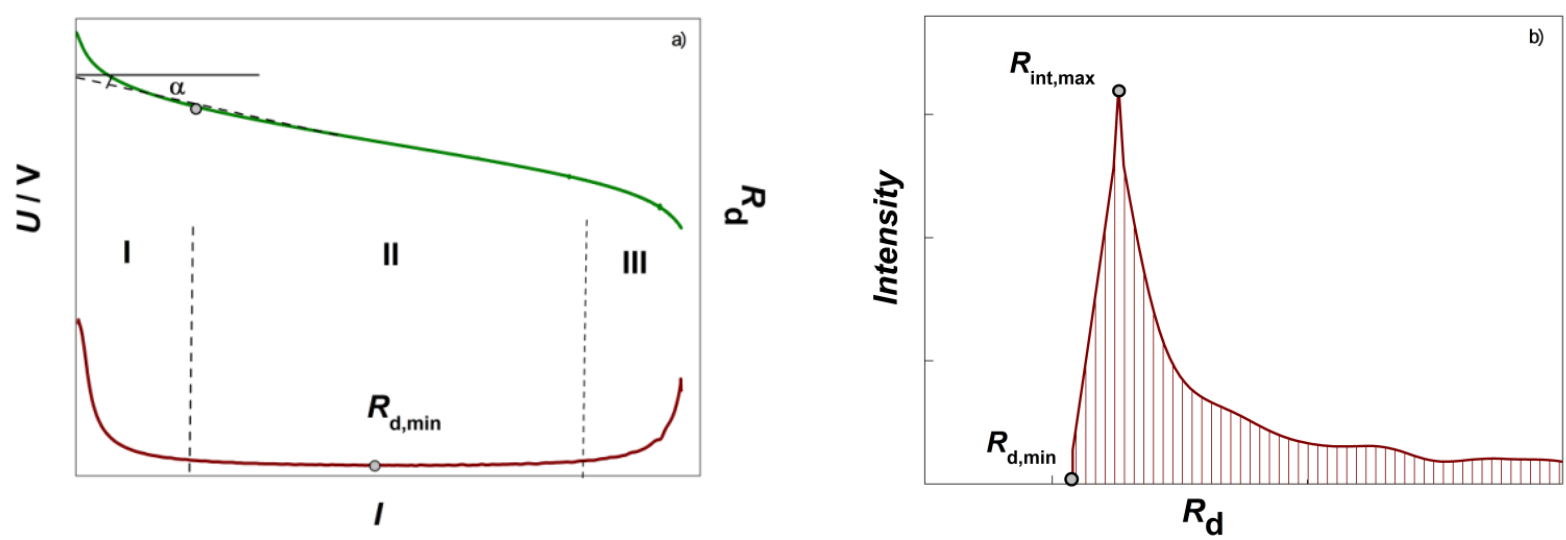

Figure 5. Differential Resistance Analysis - schematic representation:

a) U-I curve (-) and R vs. I dependence (-); b) spectral transform

The impedance of the investigated electrochemical system depends on the selected working point, i.e. measurements carried out in different working points are not comparable. Usually when the degradation rate is under studies, they are performed at constant current corresponding to the one selected for the testing. However, the extraction of $R_{\mathrm{d} \text {,min }}$ defines a working point which is constant in respect to the internal state of the system, i.e. to its state of health, characterized with the smallest internal differential resistance for the conditions of the $i-U$ curve. In addition, due to the analysis of derivatives, the changes in $R_{\mathrm{d} \text {,min }}$ will be observable much earlier than changes in other parameters, which are used for evaluation of SoH.

The introduction of a spectral transform procedure additionally increases the noise immunity and sensitivity of the method (Figure $5 b)[32,33]$. The intensity of the individual spectral peak $\left(A \Omega^{-1} \mathrm{~cm}^{-4}\right)$ is proportional to the length of the current range with similar values of the differential resistance.

The operation with derivatives increases the data noise. In order to provide high quality data, $Z$. Stoynov developed recommendations for current-voltage measurements when applying DiVA [49].

The Differential Resistance Analysis, which uses the new characteristic indicator $R_{\mathrm{d} \text {, min, }}$ is several times more sensitive than the classical approach for measurement of the degradation rate based on the voltage change over time at constant current [30-32]. Figure 6 demonstrates the high selectivity and sensitivity of the method that makes visible changes in the system which are unnoticeable in the current-voltage characteristics and ensures their quantitative evaluation. The combination of Differential Resistance Analysis with impedance measurements in selected characteristic working points can provide information about the origin of the dominating degradation processes. 

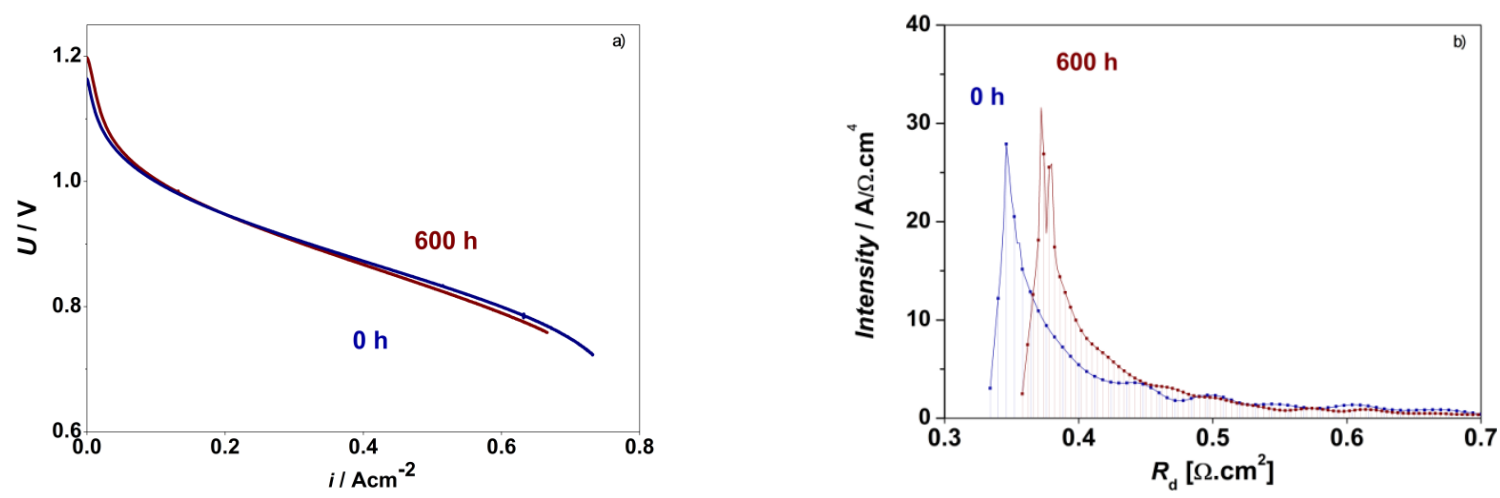

Figure 6. Differential Resistance Analysis of a Solid Oxide Fuel Cell: (a) i-U curve measured in the beginning of the testing and after 600 hours; b) spectral transform of the differential resistance $R_{d .}$

\section{Instead of conclusion}

The memory of Zdravko Stoynov is persistent, as are his methods. All that he has sown and nurtured will continue to bear fruit into the future.

\section{References}

[1] P. Lazarova, Annual of the National Polytechnic Museum 10 (1980) 149 (in Bulgarian).

[2] Z. Stoynov, W. Obretenov, Bulgarian Chemical Communications 49 C (2017) 42-50.

[3] E. Budevski, W. Bostanov, T. Vitanov, Z. Stoynov, A. Kotzewa, R. Kaischew, Electrochimica Acta 11 (1966) 1697.

[4] E. Budevski, W. Bostanov, Z. Stoynov, A. Kotzewa, R. Kaischew, Physica Status Solidi 13 (1966) 577-588.

[5] M. Keddam, Z. Stoynov, H. Takenouti, Journal of Applied Electrochemistry 7 (1977) 539-544.

[6] Z. Stoynov, B. Savova-Stoynov, Journal of Electroanalytical Chemistry 183 (1985) 133-144.

[7] B. Savova-Stoynov, Z. Stoynov, Electrochimica Acta 37 (1992) 2353-2355.

[8] Z. Stoynov, Electrochimica Acta 38 (1993) 1919.

[9] Z. Stoynov, B. Savova, Journal of Electroanalytical Chemistry 112 (1980) 157-161.

[10] Z. Stoynov, in NATO Science Series 3. High Technology, C. Julien, Z. Stoynov (Eds.), Kluwer Academic Publishers, 85, 2000 p.359.

[11] Z. Stoynov, B. Savova-Stoynov, T. Kossev, Journal of Power Sources 30 (1990) 275-285.

[12] Z. Stoynov, T. Nishev, V. Vacheva, N. Stamenova, Journal of Power Sources 64 (1997) 189-192.

[13] Z. Stoynov, D. Vladikova, in Portable and Emergency Energy Sources, Z. Stoynov, D. Vladikova (Eds.), Marin Drinov Academic Publishing House, Sofia, 2006, p. 411.

[14] M. Itagaki, N. Kobari, S. Yotsuda, K. Watanabe, S. Kinoshita, M. Ue, Journal of Power Sources 135 (2004) 225-261.

[15] M. Itagaki, S. Yotsuda, N. Kobari, K. Watanabe, S. Kinoshita, M. Ue, Electrochimica Acta 51 (2006) 16291635.

[16] M. Ujvári, D. Zalka, S. Vesztergom, S. Eliseeva, V. Kondratiev, G.G. Láng, Bulgarian Chemical Communications 49 C (2017) 106-113.

[17] V. Horvat-Radošević, K. Kvastek, K. Magdić Košiček, Bulgarian Chemical Communications, 49 C (2017) 119-127.

[18] Bio-Logic website, support section https://www.bio-logic.net/wp-content/uploads/WP2-Systems.pdf (05/09/2019)

[19] Z. Stoynov, D. Vladikova, in Portable and Emergency Energy Sources, Z. Stoynov, D. Vladikova (Eds.), Marin Drinov Academic Publishing House, Sofia, 2006, p. 437. http://www.bio-logic.net/wpcontent/uploads/EC-BT-Lab-AN57.pdf

[20] Z. Stoynov, Electrochimica Acta 34 (1989) 1187-1192.

[21] Z. Stoynov, Polish Journal of Chemistry 71 (1997) 1204-1210.

[22] Z. Stoynov, in NATO Science Series, 3. High Technology, C. Julien, Z. Stoynov (Eds.), Kluwer Academic Publishers 85, 2000, p. 371.

[23] D. Vladikova, Z. Stoynov, Journal of Electroanalytical Chemistry 572 (2004) 377-387. 
[24] D. Vladikova, P. Zoltowski, E. Makowska, Z. Stoynov, Electrochimica Acta 47 (2002) 2943-2951.

[25] Z. Stoynov, D. Vladikova, Differential Impedance Analysis, Marin Drinov Publ. House, Sofia, 2005.

[26] Z. Stoynov, D. Vladikova, in Encyclopedia of Electrochemical Power Sources, U. Garche (Ed.), Elsevier, 2009, p. 632

[27] Z. Stoynov, Fourier Analysis in the Presence of Nonstationary Periodic Noise, Dissertation No 1839, Swiss Federal Institute of Technology, Zurich, 1985.

[28] Z. B. Stoynov, Electrochimica Acta, 37 (1992) 2357-2359.

[29] Z. Stoynov, Bulgarian Chemical Communications 50 D (2018) 123-130.

[30] Z. Stoynov, D. Vladikova, B. Burdin, J. Laurencin, D. Montinaro, Ar. Nakajo, P. Piccardo, Al. Thorel, M. Hubert, R. Spotorno, A. Chesnaud, MRS Advances 2 (2017) 3991-4003. http://dx.doi.org/10.1557/adv.2017.592

[31] Z. Stoynov, D. Vladikova, B. Burdin, Bulgarian Chemical Communications 50 D (2018) 21-30.

[32] Z. Stoynov, D. Vladikova, B. Burdin, J. Laurencin, D. Montinaro, G. Raikova, G. Schiller, P. Szabo, Applied Energy 228 (2018) 1584-1590.

[33] Z. Stoynov, B. Savova-Stoynov, Journal of Electroanalytical Chemistry 170 (1984) 63-76.

[34] Q.-A Huang, R. Hue, B. Wang, J. Zhang, Electrochimica Acta 52 (2007) 8144-8164.

[35] Mark E. Orazam, Bernard Tribollet, Electrochemical Impedance Spectroscopy, Wiley and Sons, Hoboken, New Jersey, 2008.

[36] Handbook of Fuel Cells - Fundamentals, Technology and Applications/Advances in Electrocatalysis, Materials, Diagnostics and Durability; S. H. Jensen, J. Hjelm, A. Hagen, M. Mogensen, DOI:10.1002/ /9780470974001.f500053, Copyright @ John Wiley \& Sons, Ltd., 2010.

[37] Andrzej Lasia, Electrochemical Impedance Spectroscopy and its Applications, ISBN 978-1-4614-8932-0, ISBN 978-1-4614-8933-7 (e-Book), DOI 10.1007/978-1-4614-8933-7, Springer, New York, 2014.

[38] M. Viviani, M. Buscaglia, L. Mitoseru, A. Testino, P. Nani, D. Vladikova, Journal of the European Ceramic Society 24 (2004) 1221-1225.

[39] D. Vladikova, A. Kilner, S. J. Skinner, G. Raikova, Z. Stoynov, Electrochimica Acta 51 (2006) 1611-1621.

[40] D. Vladikova, G. Raikova, Z. Stoynov, H. Takenouti, J. Kilner, St. Skinner, Solid State Ionics 176 (2005) 2005-2009.

[41] A. Barbucci, M. Viviani, P. Carpanese, D. Vladikova, Z. Stoynov, Electrochimica Acta 51 (2006) 16411650.

[42] D. Vladikova, Z. Stoynov, A. Barbucci, M. Viviani, P. Carpanese, G. Raikova, in New Developments in Advanced Functional Ceramics, L. Mitoseriu (Ed.), Kerala, India, 2007, Ch. 16, p. 457.

[43] A. Kirchev, Journal of Power Sources, 170 (2007) 495-512.

[44] A. Kirchev, Journal of Power Sources, 179 (2008) 808-818.

[45] A. Kirchev, Journal of Power Sources, 191 (2009) 82-90.

[46] D. Vladikova, Z. Stoynov, G. Raikova, A. Thorel, A. Chesnaud, J. Abreu, M. Viviani, A. Barbucci, S. Presto

[47] P. Carpanese, Electrochimica Acta 56 (2011) 7955-7962.

[48] D. Vladikova, Z. Stoynov, A. Chesnaud, A. Thorel, M. Viviani, A. Barbucci, G. Raikova, P. Carpanese, M. Krapchanska, E. Mladenova, International Journal of Hydrogen Energy, 39 (2014) 21561-21568.

[49] Z. Stoynov, D. Vladikova, B. Burdin, in Handbook of Test Procedures and Protocols, Chapter 3: Endurance, Procedures and Protocols, http://www.durablepower.eu/index.php/handbook.

(C2020 by the authors; licensee IAPC, Zagreb, Croatia. This article is an open-access article distributed under the terms and conditions of the Creative Commons Attribution license (http://creativecommons. org/licenses/by/4.0/) 